
AL-AZHAR
Dental Journal
The Official Publication
of The Faculty of Dental
Medicine For Girls,
F o r
$\mathrm{G} \quad \mathrm{i} \quad \mathrm{r} \quad \mathrm{l} \quad \mathrm{s}$
Al-Azhar University
Cairo, Egypt.

ADJ-for Grils, Vol. 4, No. 3, July (2017) — PP. 279:287

\title{
Evaluation of Smear Layer Removal and Calcium Ions Concentration in Intraradicular Dentin Treated with Apple Vinegar (SEM Study)
}

\author{
Hebatullah A. Safwat ${ }^{(1)}$, Mohsen Nour EI Deen ${ }^{(2)}$, Hagar A.EI Naby Bastawy ${ }^{(3)}$
}

Codex : 33/1707

dentaljournal.forgirls@yahoo.com

\section{KEYWORDS}

Apple vinegar,

Smear layer removal,

Calcium ion content.

\begin{abstract}
Aim: This study was conducted to evaluate the smear layer removal efficiency of apple vinegar and EDTA when used as final rinse using scanning electron microscope (SEM) and to quantify the calcium content of intraradicular dentin after being treated with apple vinegar or EDTA using energy dispersive X-ray microanalyzer (EDX). Materials and methods: Fifty palatal roots of extracted human permanent maxillary molars with completely formed were selected and prepared with Universal Protaper rotary files. After using each file, canals were irrigated with $2 \mathrm{ml}$ of $2.6 \% \mathrm{NaOCl}$ for 1 minute. The samples were divided into 4 groups according to the final rinse used and the application time: (10 samples each), Group I: 17\% EDTA for 1 minute.Group II: Apple vinegar for 1 minute. Group III: $17 \%$ EDTA for 3 minutes.Group IV: Apple vinegar for 3 minutes.Group V: control group is divided into: GV(A), Five samples where the root canals were irrigated with sterile saline and $G V(B)$, Five samples were used to assess the calcium content with energy dispersive X-ray microanalyzer (EDX), where the root canals will not receive any treatment. Results: Regarding smear layer removal, at coronal and middle thirds there was no statistically significant difference in the mean scores of smear layer produced by the tested groups.At the apical third the lowest mean smear layer score was recorded in specimens treated with apple vinegar for 1 minute (Group II) with a statistical significant difference from specimens treated with $17 \%$ EDTA for 1 minute (Group I). Regarding the calcium content, the highest mean value was recorded in specimens treated with apple vinegar for 1 minute (Group II) with statistically significant difference from that recorded in specimens treated with 17\% EDTA for 1 minute (Group I) and specimens treated with apple vinegar for 3 minutes (Group IV). Conclusion: Apple vinegar was capable of adequately removing smear layer from intraradicular dentin when used as final rinse.Apple vinegar was more effective in removing smear layer from intraradicular dentin at the apical third compared to $17 \%$ EDTA. Apple vinegar was more effective when used for one minute as final rinse in the removal of smear layer without affecting the calcium content of intraradicular dentin compared to $17 \%$ EDTA.
\end{abstract}

A paper extracted from Master Thesis entitled "Evaluation of Smear Layer Removal and Calcium Ions Concentration in Intraradicular Dentin Treated with Apple Vinegar(SEM Study)"

1. Demonstrator, Endodontic Department, Faculty of Dental Medicine for Girls, Al-Azhar University.

2. Professor of Endodontics, Endodontic Department, Faculty of Dental Medicine for Girls, Al-Azhar University.

3. Associate Professor of Endodontics, Endodontic Department, Faculty of Dental Medicine for Girls, Al-Azhar University. 


\section{INTRODUCTION}

The success of the endodontic treatment depends on thorough debridement of the root canal system. During canal preparation, dentin chips created by the action of endodontic instruments add to the remnants of organic material, forming a smear layer that adheres to the canal walls ${ }^{(1)}$. In an effort to remove this layer completely, a number of irrigating solutions have been investigated. Sodium hypochlorite $(\mathrm{NaOCl})$ is the most commonly employed irrigating solution during cleaning and shaping of the root canal system. However, its capacity to remove smear layer from the instrumented root canal walls has been found to be lacking, as it only affects the organic part of the smear layer ${ }^{(2,3)}$. Chelating agents have been recommended as adjuvants in root canal treatment as they are able to remove the inorganic component of smear layer. The most common chelating solutions are based on ethylenediamine tetra acetic acid (EDTA), which is used alternatingly with $\mathrm{NaOCl}$ solutions to remove the smear layer. However, there is concern that this combined irrigation regimen causes inadvertent erosion of the intertubular and peritubular dentin, especially when EDTA applied more than 1 minute. Moreover, the chelating effect of EDTA was almost negligible in the apical third of the root canals ${ }^{(2,4)}$.

The components of the smear layer are very small particles with a large surface-mass ratio, which makes them very soluble in acids. Weak acids such as citric acid, malice acid and apple vinegar have been introduced to minimize the harmful effect of EDTA on dentin. The use of apple vinegar as solution aid in the chemomechanical preparation has been proposed in endodontics and deserves special attention, due to its promising results, when compared to other auxiliary solutions most commonly used in endodontics such as EDTA and sodium hypochlorite ${ }^{(4)}$. Moreover, the effectiveness of vinegar on the endodontic microbiota, physicochemical properties and their role in the apical and periapical repair process have been developed ${ }^{(5)}$.
Apple vinegar is a combination of acetic, citric, formic, lactic, succinate and tartaric acids with small quantities of alcohol resulting from the fermentation process and it is responsible for reducing the surface tension of the solution. However, the highest acid concentrations of the vinegar are represented by the acetic $(5 \%)$ and malic $(0.35 \%)$ acids. Malic acid may boost the immune system with power supply within the cells, because it is one of the acids in the Krebs cycle ${ }^{(6)}$.

The influence of different types of vinegar (white, apple, rice, white wine and vinegar) on the removal of smear layer and exposure of dentinal tubules has been evaluated. The results showed that the vinegars can remove the smear layer of the root surface and exposed dentinal tubules. The balsamic vinegar was associated with less removal of smear layer from the other tested types ${ }^{(7)}$. In a subsequent study, the cleaning of root canal promoted by apple vinegar, $2.5 \%$ sodium hypochlorite, $2 \%$ chlorhexidine and combinations of those drugs with EDTA has been analyzed by SEM. The combination of EDTA to irrigating solutions significantly increased cleaning capacity of all solutions. The best result was obtained by apple cider vinegar combined with EDTA $^{(4)}$. The smear layer removal with several root canal chelators (15\% EDTA, $10 \%$ citric acid, $10 \%$ sodium citrate, apple vinegar, $5 \%$ acetic acid, $5 \%$ malic acid, and $1 \% \mathrm{NaOCl}$ ) has been verified and concluded that EDTA and citric acid were the most efficient solutions in removing smear layer ${ }^{(8)}$. It has been concluded that the apple vinegar associated or not with EDTA was more effective in removing smear layer from the root canals than $\mathrm{NaOCl}$ associated with $\operatorname{EDTA}^{(9)}$.

When the efficiency of EDTA, apple vinegar and Smear Clear, with and without ultrasonic activation, on smear layer removal has been evaluated, it has been found that ultrasonics did not improve the smear layer removal significantly in all groups. The lowest smear layer removal capacity was observed in the apical third of the root canal, with statistical differences between the coronal third in 
all irrigation regimens ${ }^{(10)}$.However, when the smear layer removal resulting from final irrigation with different chelating solutions has been evaluated by using, apple vinegar, 5\% malic acid, 5\% acetic acid, 17\% EDTA, and distilled water (control). It has been reported that, there was statistically significant difference between 17\% EDTA and the other solutions with regard to smear layer removal. Apple vinegar, 5\% malic acid, and 5\% acetic acid promoted similar root canal cleaning. There was no statistical difference among the root canal thirds ${ }^{(11)}$.

Dentin is composed of the various inorganic component of dental hard tissue, present as hydroxyapatite crystals in the form of calcium and phosphorous. In hydroxyapatite crystals $\mathrm{Ca} / \mathrm{P}$ ratio has been established at 1.67 approximately. This ratio depends on many factors such as level of mineraliation, type of crystals, the age of tissue and anatomical site $^{(12)}$.

It has been reported that some chemicals used for endodontic irrigation are capable of causing alteration in the chemical composition of dentin. Any change in the $\mathrm{Ca}^{2+}$ ratio may change the original proportion of organic and inorganic components, which in turn changes the microhardness, permeability and solubility characteristics of dentin and may also adversely affect the sealing ability and adhesion of dental materials such as resin-based cements and root canal sealers to dentin. Indeed, dentin adhesion depends on the presence of residual $\mathrm{Ca}^{2+}$ on the bonding area, and there is evidence that partial depletion of surface $\mathrm{Ca}^{2+}$ may significantly reduce the bond strength of some adhesive materials ${ }^{(13-21)}$.

Calcium ion removal with different root canal chelators (15\% EDTA, $10 \%$ citric acid, $10 \%$ sodium citrate, apple vinegar, 5\% acetic acid, 5\% malic acid, and sodium hypochlorite) was evaluated. Results showed that $15 \%$ EDTA solutions removed the highest concentration of calcium ions followed by $10 \%$ citric acid, when compared with $10 \%$ sodium citrate, apple vinegar, $5 \%$ acetic acid, and $5 \%$ malic acid ${ }^{(8)}$.In another study, calcium ion release resulting from final irrigation with different chelating solutions has been quantified. Chelating solutions were apple vinegar, 5\% malic acid, 5\% acetic acid, 17\% EDTA and distilled water (control). The highest concentrations of calcium ions were obtained with 17\% EDTA, followed by malic acid. Apple vinegar and acetic acid removed the smallest quantity of calcium ions ${ }^{(11)}$.

Little data was published regarding the cleaning ability of the apple vinegar in when used as final rinse in endodontic irrigation and its effect on calcium ion content of intraradicular dentin substrate. Therefore, this study was directed to evaluate the smear layer removal efficiency of apple vinegar and EDTA when used as final rinse using scanning electron microscope (SEM) and to quantify the calcium content of intraradicular dentin after being treated with apple vinegar or EDTA using energy dispersive $\mathrm{X}$-ray microanalyzer (EDX).

\section{Materials and methods}

Fifty palatal root canals of extracted permanent human maxillary molars with completely formed roots and no evidence of cracks or fractures were selected. The crowns were decapitated from the roots at the cemento-enamel junction using separating diamond disc under constant water spray. The working lengths were measured by subtracting $1 \mathrm{~mm}$ from lengths that will be recorded when the tips of \#10 K-files become observed at the apical foramina. Root apices were closed with sticky wax to simulate the closed end model. The canals were be prepared with Universal Protaper rotary files. After using each file, canals were irrigated with $2 \mathrm{ml} 2.6 \% \mathrm{NaOCl}$ for 1 minute dispensed through a 31-gauge Navi-Tip flexible irrigation needle, where the needle was inserted as deep as possible into the root canal without binding. The total volume of the irrigating solution used was $12 \mathrm{ml}$ of $2.6 \% \mathrm{NaOCl}$. After root canal preparation, the samples were divided into four experimental groups (I, II, III, IV) according to the final rinse used and the application time and one control group (V) (10 samples each).Group I: $17 \%$ 
EDTA for 1 minute ${ }^{(22)}$,Group II: Apple vinegar for 1 minute,Group III: $17 \%$ EDTA for 3 minutes,Group IV: Apple vinegar for 3 minutes $^{(10)}$.The canals were irrigated with $5 \mathrm{ml}$ distilled water and dried with paper points.Group V: Control group which were divided into: a)Five samples were irrigated with sterile saline and b) Five samples were not receive any treatment to assess the calcium content with energy dispersive $\mathrm{X}$-ray (EDX).

All teeth were grooved longitudinally on the external surfaces (buccal \&lingual) with a diamond disk, avoiding penetration of the root canals. The teeth were then carefully split with a chisel and mallet into two halves. Each specimen was measured length wise with a digital caliper from the cementoenamel junction (CEJ) to the apex for delimitation of the root thirds (segments). Starting from the CEJ, the points corresponding to $1 / 6$, $3 / 6$ and $5 / 6$ of the root length were demarcated to indicate the half of the coronal, middle and apical thirds respectively. The cleanliness of the root canals and smear layer were evaluated at three levels of root canal (coronal, middle and apical) using environmental scanning electron microscope (FEI Quanta ESEM) Photomicrographs were taken under magnification (X 4000) for smear layer scores at the apical, middle and coronal thirds of the canals and analyzed by means of numerical evaluation score by Hülsmann et al. ${ }^{(23)}$ as following:

- Score 1: No smear layer and patent dentinal tubules (clean root canal wall and only a few small debris particles).

- Score 2: Small amount of smear layer, some open dentinal tubules (a few small agglomerations of debris).

- Score 3: Homogenous smear layer covering the root canal wall, only few open dentinal tubules (many agglomerations of debris covering less than $50 \%$ of the root canal wall).
- Score 4: The entire root canal wall covered with a homogenous smear layer, no open dentinal tubules (more than $50 \%$ of the root canal walls were covered with debris).

- Score 5: Heavy, nonhomogenous smear layer covering the entire root canal wall (complete or nearly complete root canal wall coverage with debris).

The mineral content of root canal dentin was measured using Energy Dispersive X-ray (EDX). $\mathrm{X}$-ray microanalysis relies on the ability to detect $\mathrm{X}$-rays generated when a specimen is bombarded with high-energy electrons in an electron microscope. The X-rays can be detected using an energy-dispersive spectrometer, which can separate $\mathrm{X}$-rays with different energy levels.

\section{Statistical analysis}

Data were calculated and statistically analyzaed, for parametric data; one-way ANOVA test was used to compare between the different groups while for non-parametric data; Kruskal-Wallis test was used.

\section{RESULTS}

\section{Smear layer removal (Table 1) and (Figure 1)}

At coronal and middle level: Results showed that there was no statistically significant difference between mean smear layer scores of the experimental groups. At the apical level:The lowest mean smear layer score was recorded by samples of group II (apple vinegar 1 minute) which was statistically significant different from that of group I (17\% EDTA 1 minute), however, there was no statistically significant difference between group II (apple vinegar 1 minute), group III (17\% EDTA 3 minutes) and group IV (apple vinegar 3 minutes) (Figure 2). 
Table (1) Descriptive analysis of the smear layer scores at the coronal, middle and apical level of all tested groups.

\begin{tabular}{ccccccccccccc}
\hline \multirow{2}{*}{$\begin{array}{c}\text { Root } \\
\text { level }\end{array}$} & \multicolumn{2}{c}{ GI } & \multicolumn{2}{c}{ GII } & \multicolumn{2}{c}{ GIII } & \multicolumn{2}{c}{ GIV } & \multicolumn{2}{c}{ GV } \\
\cline { 2 - 9 } & Mean & SD & Mean & SD & Mean & SD & Mean & SD & Mean & SD & \\
Coronal & $1.7^{\mathrm{b}}$ & 0.7 & $1.6^{\mathrm{b}}$ & 0.7 & $1.5^{\mathrm{b}}$ & 0.5 & $1.4^{\mathrm{b}}$ & 0.5 & $3.6^{\mathrm{a}}$ & 1.1 & $0.013^{*}$ \\
Middle & 2.0 & 1.1 & 1.9 & 0.6 & 1.7 & 0.7 & 2.1 & 0.9 & 3.8 & 1.1 & 0.052 \\
Apical & $3.4^{\mathrm{a}}$ & 1.0 & $2.3^{\mathrm{b}}$ & 0.8 & $3.1^{\mathrm{ab}}$ & 0.9 & $2.6^{\mathrm{b}}$ & 0.8 & $3.8^{\mathrm{a}}$ & 1.1 & $0.030^{*}$ \\
Overall & 2.4 & 0.8 & 1.9 & 0.4 & 2.1 & 0.6 & 2.0 & 0.6 & 3.7 & 1.0 & 0.051 \\
\hline
\end{tabular}

*: Significant at $P \leq 0.05$, Different superscripts in the same row are statistically significantly different

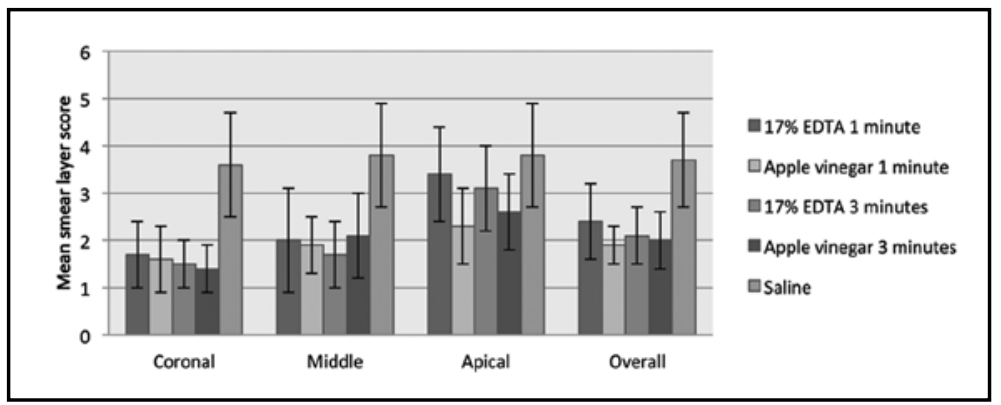

Fig. (1) A bar chart comparing the mean scores of smear layer and standard deviation among 17\% EDTA 1 minute, apple vinegar 1 minute, $17 \%$ EDTA 3 minutes, apple vinegar 3 minutes and saline groups at the coronal, middle and apical levels.

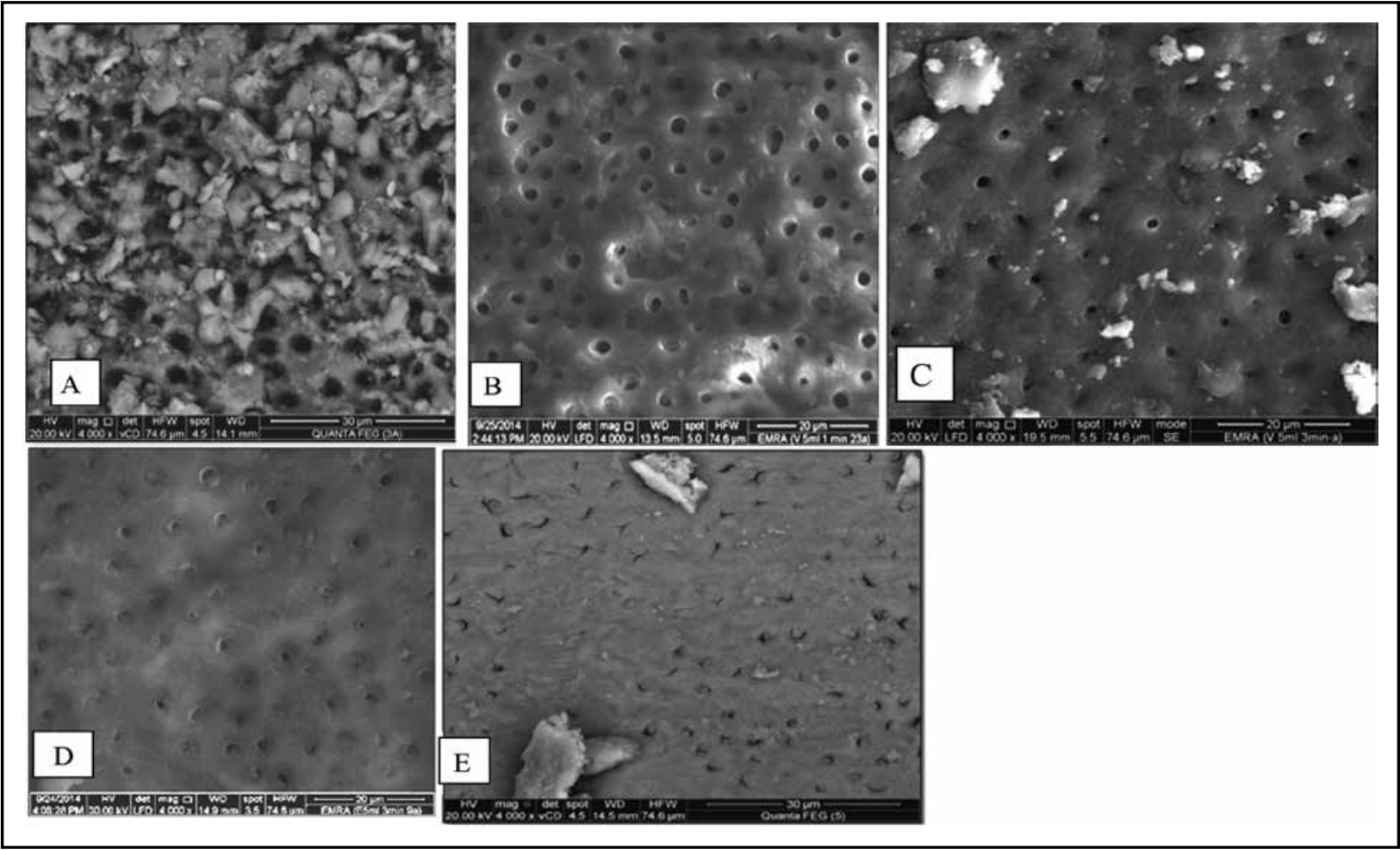

Fig. (2) A scanning photomicrograph of the apical level of a root canal rinsed with A)Group I: $17 \%$ EDTA 1 minute (score 4 , X 4000).B) Group II: Apple vinegar 1 minute(score 2, X 4000).C) Group III: 17\% EDTA 3 minutes (score 3, X 4000). D) Group IV: Apple vinegar 3 minutes (score 3, X 4000) . E) Group V: Saline (score 4,X 4000) 


\section{II.Calcium content}

\section{Comparison of the mean calcium content among the tested groups:}

(Table 2) and (Figure 3)

The results showed that the highest mean calcium content was recorded in specimens treated with apple vinegar for 1 minute (group II), which revealed statistically significant difference from that of specimens treated with 17\% EDTA for 1 minute (group I) and that of specimens treated with apple vinegar for 3 minutes (group IV).

Table (2) Descriptive analysis of the calcium content of all tested groups.

\begin{tabular}{llll}
\hline \multicolumn{1}{c}{ Group } & Mean & SD & $\boldsymbol{P}$-value \\
\hline GI (17\% EDTA 1 min.) & $22.8^{\mathrm{b}}$ & 6.2 & \\
GII (Apple vinegar 1 min.) & $29.5^{\mathrm{a}}$ & 5.7 & \\
GIII (17\% EDTA 3 min.) & $26.2^{\mathrm{ab}}$ & 4.4 & \\
GIV (Apple vinegar 3 min.) & $22.5^{\mathrm{b}}$ & 3.0 & \\
GV a (Saline) & $31.1^{\mathrm{a}}$ & 4.4 & \\
GV b (No irrigation) & $28.8^{\text {ab }}$ & 4.2 &
\end{tabular}

*: Significant at $P \leq 0.05$, Different superscripts are statistically significantly different

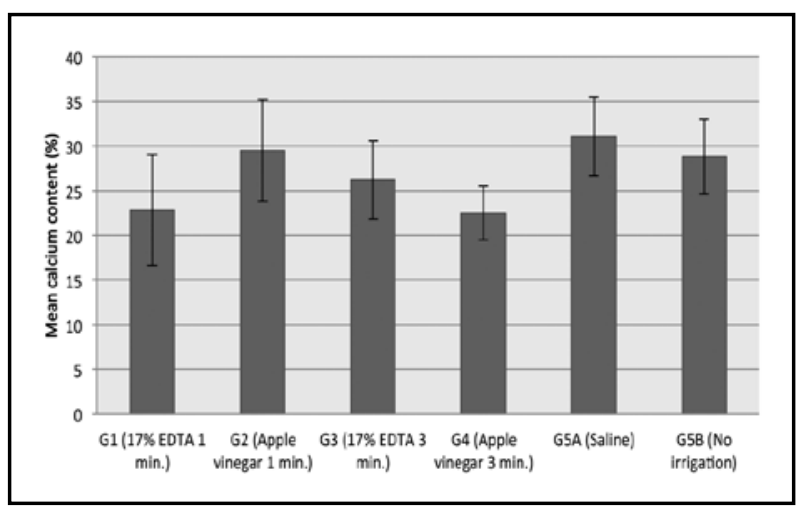

Fig. (3) A bar chart comparing the mean calcium content and standard deviation among 17\% EDTA 1 minute, apple vinegar 1 minute, 17\% EDTA 3 minutes, apple vinegar 3 minutes, saline groups and group without irrigation.

\section{DISCUSSION}

The main goals of the chemomechanical preparation are to eliminate bacteria and their byproducts from the root canal system, remove pulp tissue remnants and contaminated organic and inorganic debris. The search for a chelating agent that was more efficient and biocompatible than EDTA has resulted in various solutions being researched over the last few years. Accordingly, apple vinegar was used in the present study due to its biocompatibility, chelating capacity, antimicrobial potential and its cost-effectiveness ${ }^{(7,9,24)}$.

Regarding the results of smear layer removal,at the coronal level, the lowest mean scores of smear layer was recorded in specimens treated with apple vinegar for 3 minutes compared to 17\% EDTA 1 minute, 17\% EDTA 3 minutes or apple vinegar 1 minute. However, there was no statistically significant difference in the mean scores of smear layer among the tested groups either at the coronal or middle third $(\mathrm{P}>0.05)$. The results of the apple vinegar might be attributed to that apple vinegar has acids in its constitution, and the malic acid is the main component which is responsible for the therapeutic property of the apple vinegar ${ }^{(6)}$.

The lower mean smear layer score with apple vinegar reported in this study was in disagreement with previous study ${ }^{(10)}$, which revealed that the apple vinegar was not able to completely remove the smear layer, with significant difference between EDTA at the coronal third. These discrepancies might be attributed to differences in the selected teeth, where they used canines with straight roots, less volume of apple vinegar $(3 \mathrm{ml})$ and less volume of $\mathrm{NaOCl}$ irrigation.

In the current study, the lower mean smear layer score produced by apple vinegar for 1 minute at the apical level could be attributed to the decreased surface tension of the malic acid, which is the main component of apple vinegar, when compared to that of $17 \%$ EDTA $^{(25)}$. Moreover, the presence of alcohol resulting from the fermentation process of 
apple vinegar is responsible for reducing its surface tension ${ }^{(26)}$. It has been reported that, the efficiency of a root canal irrigant, depends on its intimate contact with the dentin walls and debris, which is a property that is strictly correlated to the surface tension of the irrigant ${ }^{(27,28)}$.

Moreover, the preceding use of $2.6 \% \mathrm{NaOCl}$ before the final rinse increase the efficiency of the apple vinegar, where the use of $\mathrm{NaOCl}$ dissolve the organic portion of smear layer that covers the dentinal tubules allows acids to dissolve the inorganic portion of the smear layer, penetrate into dentinal tubules, and decalcify them ${ }^{(29)}$.

The results of the present study was not consistent with a recent study reported that, 17\% EDTA was more effective regarding removal of smear layer and the difference was statistically significant ${ }^{(11)}$. This could be attributed to absence of $\mathrm{NaOCl}$ as the main irrigant was distilled water that used at every change of instrument.

The lower efficiency of EDTA to clean the apical third might be explained by that a neutral EDTA solution not only removes calcium ions but also calcium bonded to noncollagenous proteins of dentin (NCPs) ${ }^{(23,30)}$. As the content of NCPs decreased at the apical third of the root canal system, accordingly the decalcifying effect of EDTA at the apical part is low.The results of the present study regarding the low effectiveness of EDTA in cleaning the apical third were in accordance with previous studies ${ }^{(31,32)}$.

Regarding the results of calcium ion content, the highest mean calcium content was recorded in specimens treated with saline followed by specimens treated with apple vinegar for 1 minute, followed by specimens that did not receive any irrigation, with no statistically significant difference among them. Moreover, the mean calcium content in specimens treated with apple vinegar for 1 minute was statistically higher than that recorded in specimens treated with apple vinegar for 3 minutes and $17 \%$ EDTA for 1 minute $(\mathrm{P} \leq 0.05)$.
The highest mean calcium content that was recorded in group $\mathrm{V}$ a (Saline) compared to group $\mathrm{V}$ $b$ (did not receive any irrigation) could be explained by the variable effect of $\mathrm{NaOCl}$ as irrigating solution on mineral content of root dentin, where it has been reported that treatment with sodium hypochlorite may causes mineral accumulation in human root dentin ${ }^{(33)}$. Moreover, it has been demonstrated that the use of $2.5 \%$ sodium hypochlorite as irrigation solution, either alone or combined with a $17 \%$ EDTA solution, significantly increases the $\mathrm{Ca} / \mathrm{P}$ ratio of root dentin ${ }^{(18)}$.

Regarding the highest mean calcium content recorded in specimens treated with apple vinegar applied for 1 minute compared to $17 \%$ EDTA, could be explained by the mechanism by which the calcium ions were removed, using EDTA the mechanism is by chelation while that in apple vinegar is by decalcification ${ }^{(34)}$. Moreover, malic acid is highly acidic, so it has a better demineralizing effect within a shorter period of time.

EDTA form a stable complex with the calcium ions in dentin. Accordingly, carboxyl groups of the EDTA molecule are ionized, releasing hydrogen atoms that compete with the calcium ions. When all available ions have been bound, equilibrium is formed and no further dissolution takes place. It has been concluded that the properties of EDTA were self-limiting. This limitation due to $\mathrm{pH}$ changes during demineralization of dentin. Under neutral conditions, the exchange of calcium from the dentin by hydrogen results in a subsequent decrease in $\mathrm{pH}$. Accordingly, the release of acid, decreases the efficiency of EDTA with time. Therefore, increasing time of application of $17 \%$ EDTA does not necessitate more removal of calcium ions ${ }^{(35,36)}$.

The results of the present study was consistent with previous study which reported that $17 \%$ EDTA significantly removed higher quantity of calcium ions from the root canal compared to those obtained with apple vinegar ${ }^{(11)}$. Moreover, other studies verified that apple vinegar was less effective than $17 \%$ EDTA in removing the calcium ions from the root canal ${ }^{(8,11)}$. 


\section{CONCLUSION}

\section{Within the limitations of this study the following could be concluded:}

1. Apple vinegar was capable of adequately removing smear layer from intraradicular dentin when used as final rinse.

2. Apple vinegar was more effective in smear layer removal from intraradicular dentin at the apical third compared to $17 \%$ EDTA.

3. Apple vinegar was more effective when used for one minute as final rinse in the removal of smear layer without affecting the calcium content of intraradicular dentin compared to $17 \%$ EDTA.

Further studies are recommended to investigate the effect of application time less one minute of apple vinegar on the smear layer removal, evaluate of the effect of apple vinegar on microhardnss of intraradicular dentin, evaluate the effect of apple vinegar on the roughness and hence the adhesive characteristics of dentin substrate and to evaluate effect of different irrigating delivery systems on cleaning ability of apple vinegar.

\section{REFERENCES}

1. Torabinejad M, Handysides R, Khademi AA, Bakland LK Clinical implications of the smear layer in endodontics: a review. Oral Surg Oral Med Oral Pathol Endod 2002; 94:658-66.

2. Chow TW. Mechanical effectiveness of root canal irrigation. Endod J 1983; 9: 475-9.

3. Estrela C, Estrela CR, Barbin EL, Spanó JC, Marchesan MA, PécoraJD. Mechanism of action of sodium hypochlorite. Braz Dent J 2002; 13: 113-7.

4. Estrela C, Lopes HP, Elias CN, Leles CR, Pécora JD. Cleanliness of the surface of the root canal by apple vinegar, sodium hypochlorite, chlorhexidine and EDTA. Rev Assoc Paul Cir Dent 2007; 61: 177-82.

5. Estrela C, Holland R, Bernabé PFE, Souza V, Estrela CRA. Antimicrobial potential of medicaments used in healing process in dogs' teeth with apical peridontitis. Braz Dent J 2004; 15: 181-5
6. Caligiani A, Acquotti D, Palla G, Bocchi V. Identification And Quantification Of the main organic components of vinegars by high resolution $1 \mathrm{H} \mathrm{Nmr}$ Spectroscopy. Analyt Chim Acta 2007; 585: 110-9.

7. Zandim DL, Corrêa FO, Sampaio JE, Rossa-Júnior C. The influence of vinegars on exposure of dentinal tubules: A SEM evaluation. Braz Oral Res 2004; 18: 63-8.

8. Spanó JC, Silva RG, Guedes DF, Sousa-Neto MD, Estrela C, Pécora JD. Atomic absorption spectrometry and scanning electron microscopy evaluation of concentration of calcium ions and smear layer removal with root canal chelators. J Endod 2009; 35: 727-30.

9. Candeiro GTM, Matos IB, Costa CFE, Fonteles CSR, Vale MS. A comparative scanning electron microscopy evaluation of smear layer removal with apple vinegar and sodium hypochlorite associated with EDTA. J Appl Oral Sci 2011; 19: 639-43.

10. Rodrigues CT, Bernardineli N, Duarte MAH, Bramante CM, Andrade FB. Evaluation of EDTA, apple vinegar and SmearClear with and without ultrasonic activation on smear layer removal in different root canal levels. Dental Press Endod 2013; 3: 43-8

11. Kirchhoff AL, Viapiana R, Miranda CE, Sousa Neto MD, Cruz Filho AM. Comparison of the apple vinegar with other chelating solutions on smear layer and calcium ions removal from the root canal. Indian J Dent Res 2014; 25 : $370-4$.

12. Baumgartner CJ, Stephen Johal, J Gordon Marshall. Comparison of the Antimicrobial Efficacy of $1.3 \% \mathrm{NaOCl} /$ BioPure MTAD to $5.25 \% \mathrm{NaOCl} / 15 \%$ EDTA for root canal irrigation. J Endod, 2007; 33: 48-51.

13. Perinka L, Sano H, Hosoda H. Dentin thickness, hardness and Ca-concentration vs. bond strength of dentin adhesives . Dent Mater 1992; 8:229-33.

14. Panighi $M$ and $G$ 'Sell $C$. Influence of calcium concentration on the dentin wettability by an adhesive. J Biomed Mater Res 1992; 26:1081-9.

15. Hennequin M, Pajot J, Avignant D. Effects of different $\mathrm{pH}$ values of citric acid solutions on the calcium and phosphorus contents of human root dentin. J Endod 1994; 20:551-4

16. Swift EJ, Hammel SA, Pediago J, Wefel JS. Prevention of root surface caries using a dentin adhesive. J Am Dent Assoc 1994; 125: 571-6. 
17. Rotstein I, Dankner E, Goldman A, Heling I, Stabholz A, Zalkind M. Histochemical analysis of dental hard tissues following bleaching. J Endod 1996; 22:23-6.

18. Dogan $\mathrm{H}$ and Calt $\mathrm{S}$. Effects of chelating agents and sodium hypochlorite on mineral content of root dentin. J Endod 2001; 27:578-80.

19. Perdigao J, Eiriksson S, Rosa BT, Lopes M, Gomes G. Effect of calcium removal on dentin bond strengths. Quintessence Int 2001; 32: 142-6.

20. Ari $\mathrm{H}$ and Erdemir A. Effects of endodontic irrigation solutions on mineral content of root canal dentin using ICP-AES technique. J Endod 2005; 31:187-9.

21. Garcia-Godoy F, Loushine RJ, Itthagarun A, Weller RN, Murray PE, Feilzer AJ, Pashley DH, Tay FR. Application of biologically-oriented dentin bonding principles to the use of endodontic irrigants. Am J Dent 2005; 18: 281-90.

22. Teixeira CS, Felippe MC, Felippe WT. The effect of application time of EDTA and $\mathrm{NaOCl}$ on intracanal smear layer removal: an SEM analysis. Int Endod J 2005; 38: 285-90.

23. Hülsmann M, Rümmelin C, Schäfers F. Root canal cleanliness after preparation with different endodontic handpieces and hand instrument. A comparative SEM investigation. J Endod 1997; 23:301-6.

24. Costa D, Dalmina F, Irala LED. The use of the vinegar as a chemical auxiliary in endodontics: a literature review. RSBO. 2009; 6: 185-93.

25. Ballal NV, Kandian S, Mala K, Bhat KS, Acharya S. Comparison of the efficacy of maleic acid and ethylene diamine tetraacetic acid in smear layer removal from instrumented human root canal: a scanning electron microscopic study. J Endod 2009; 35:1573-6.

26. Budak NH, Aykin E, Seydim AC, Greene AK, GuzelSeydim ZB. Functional properties of vinegar. J Food 2014; 79: 757-64.
27. Pecora JD, Guimaraes LF, Savioli RN. Surface tension of several drugs used in endodontics. Braz Dent J. 1992; 2:123-7.

28. Tasman F, Cehreli ZC, Ogan C, Etikan I. Surface tension of root canal irrigants. J Endod 2000; 26:586-7.

29. Torabinejad M, Khademi AA, Babazoli J, Cho Y, Jonhson WB, Bozhilov K et al. A new solution for the removal of the smear layer. J Endod 2003; 29: 170-5.

30. Khademi A, Yazdizadeh M, Feizianfard M. Determination of the minimum instrumentation size for penetration of irrigants to the apical third of root canal systems. J Endod 2006; 32: 417-20.

31. Rathakrishnan M, Sukumaran VG, Subbiya A. Efficacy of an Innovative Irrigant on Smear Layer Removal - SEM Analysis. JCDR 2016; 10: 104-6.

32. Prabhu SG, Rahim N, Bhat KS, Mathew J. Comparison of removal of endodontic smear layer using sodium hypochlorite, EDTA and different concentrations of maleic acid: a SEM study. Endodontol 2003; 15: 20-5.

33. Inaba D, Ruben J, Takagi O, Arends J. Effect of sodium hypochlorite treatment on remineralization of human root dentine in vitro. Caries Res 1996; 30: 218-24.

34. Machado-Silveiro LF, González-López S, GonzálezRodríguez MP. Decalcification of root canal dentin by citric acid, EDTA and sodium citrate. Int Endod J 2004; 37:365-9.

35. Hülsmann M, Heckendorf M, Lennon À. Chelating agents in root canal treatment: mode of action and indications for their use. Int Endod J 2003; 36: 810-30.

36. Seidberg BH and Schilder H. An evaluation of EDTA in endodontics. Oral Surg Oral Med Oral Pathol 1974; 37:609-20. 